The author reported no conflicts of interest.

The Journal policy requires editors and reviewers to disclose conflicts of interest and to decline handling or reviewing manuscripts for which they may have a conflict of interest. The editors and reviewers of this article have no conflicts of interest.

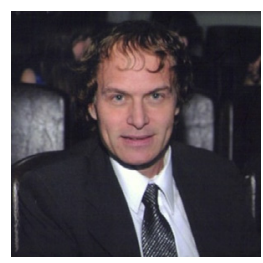

\section{RISK SCORES: TOOLS WITH LIMITATIONS THAT DO NOT REPLACE CLINICAL JUDGMENT BUT ONLY COMPLEMENT IT}

\section{To the Editor:}

I have read with attention the article by Cho and colleagues ${ }^{1}$ in which they evaluated the association among the Controlling Nutritional Status score, prognostic nutritional index, and Geriatric Nutritional Risk Index with 1-year mortality in 1927 patients undergoing valvular heart surgery. The authors clearly stated how, by adding a preoperative nutritional assessment to the European System for Cardiac Operative Risk Evaluation II, it improves its predictive ability, especially with the Controlling Nutritional Status score. ${ }^{1}$ The authors must be congratulated for such an interesting publication that discusses the importance of assessing frailty parameters such as nutritional status of the patient in preoperative risk stratification.

Risk scores are tools that should be considered as a complement for clinical judgment in the decision-making process for a given patient. In fact, since risk scores are based on mathematical models, they may exhibit many limitations. A mathematical model attempting to define a biological and binary phenomenon such as "dead or alive" is a population-based statistical analysis but not an individual one. This may result in a loss of predictive power. One of the most important limitations of risk scores is the fact they have been constructed on the basis of regional data set about specific surgical procedures. ${ }^{2}$ Furthermore,

\footnotetext{
The Editor welcomes submissions for possible publication in the Letters to the Editor section that consist of commentary on an article published in the Journal or other relevant issues. Authors should: • Include no more than 500 words of text, three authors, and five references. • Type with double-spacing. • See http://jtcs.ctsnetjournals.org/ misc/ifora.shtml for detailed submission instructions. - Submit the letter electronically via jtcvs.editorialmanager.com. Letters commenting on an article published in the JTCVS will be considered if they are received within 6 weeks of the time the article was published. Authors of the article being commented on will be given an opportunity of offer a timely response ( 2 weeks) to the letter. Authors of letters will be notified that the letter has been received. Unpublished letters cannot be returned.

Copyright (c) 2021 The Author(s). Published by Elsevier Inc. on behalf of The American Association for Thoracic Surgery. This is an open access article under the CC BY-NC-ND license (http://creativecommons.org/licenses/by-nc-nd/4.0/).
}

a loss in performance and efficiency can also be observed when they are not properly upgraded. The presence of frailty in the patient increases their risk, and this must be identified and quantified and should be entered into the equation that allows an estimated risk to be calculated. Preoperative nutritional assessment is an important metric in assessing postoperative risk. This assessment might be further improved by assessing mobility, cognitive status, and activities of daily living, the 3 other pillars of frailty, as previously stated out by several authors.

In addition to nutritional parameters, the following should be assessed: (1) mobility, such as the Afilalo 5-meter walk test ${ }^{4}$ or the Altisen test; (2) cognitive status by means of cognitive tests, such as the Folstein Mini-Mental test or the Mini-Cog test; and (3) assessment of the patient's daily activity by different tests such as the Timed up and Go Test or by Basic and Instrumental Activities or Daily Living.

At the same time, joining the 4 aforementioned parameters, different frailty scales, such as the Edmonton Frailty Scale, Fried's scale, Rockwood's Frailty Index, Katz Index, or the Essential Frailty Toolset, should be applied. ${ }^{5}$ By associating these scales to the to the classic risk scores in cardiac surgery, the risk/benefit equation can be dramatically improved. Thus, the more accurate the risk assessment of death, the more helpful it would be to both the patient's and the heart team's management decisions.

\section{Victorio C. Carosella, MD \\ Department of Cardiology \\ Instituto Cardiovascular San Isidro \\ Sanatorio Las Lomas \\ San Isidro, Buenos Aires, Argentina}

\section{References}

1. Cho JS, Shim JK, Kim KS, Lee S, Kwak YL. Impact of preoperative nutritional scores on 1-year postoperative mortality in patients undergoing valvular heart surgery. J Thorac Cardiovasc Surg. January 5, 2021 [Epub ahead of print].

2. Omar RZ, Ambler G, Royston P, Eliahoo J, Taylor KM. Cardiac surgery risk modeling for mortality: a review of current practice and suggestions for improvement. Ann Thorac Surg. 2004;77:2232-7.

3. Bando K. Commentary: appropriate frailty measures should be incorporated into the development of accurate risk calculation models for evaluation of transcatheter aortic valve replacement candidates. J Thorac Cardiovasc Surg. 2021;161:2103-4.

4. Afilalo J, Kim S, O'Brien S, Brennan JM, Edwards FH, Mack MJ, et al. Gait speed and operative mortality in older adults following cardiac surgery. JAMA Cardiol. 2016;1:314-21.

5. Afilalo J, Lauck S, Kim DH, Lefèvre T, Piazza N, Lachapelle K, et al. Frailty in older adults undergoing aortic valve replacement: the FRAILTY-AVR study. J Am Coll Cardiol. 2017;70:689-700.

https://doi.org/10.1016/j.xjon.2021.09.024 